\title{
The Effect of Displacement Mode of Rigid Retaining Walls on Shearing Bands by Active Earth Pressure
}

\author{
Abdelkrim Sekkel \\ Moulay Tahar University \\ Dept. Civil Engineering \& Hydraulic \\ Fac. Technology \\ Labo. (L.G.C.E) \\ Saida, Algeria \\ sekkel.abdelkrim@univ-saida.dz
}

\author{
Mourad Meghachou \\ Djillali Liabes University \\ Dept. Civil Engineering \\ Fac. Technology \\ Labo. (L.G.C.E) \\ Sidi Bel-Abbes, Algeria \\ mourad_meghachou@univ-sba.dz
}

\begin{abstract}
This work treats the physical modeling of failure mechanisms by active earth pressure. This last is developed by retaining wall movement. A lot of research showed that wall displacement has a significant effect on active earth pressure. A good comprehension of active earth pressure phenomenon and its failure mechanisms help us to better conceive retaining walls. The conception of a small-scale model allowed the realization of active earth pressure tests, while displacing the mobile wall toward the outside of the massif. The studied material is that of Schneebeli; light two-dimensional material made of cylindrical plastic rollers, simulating granular non-cohesive soil. The evolution of shearing zones under continuous and discontinuous displacement modes of mobile walls by correlation pictures allows the investigation of the localization of deformations and failure mechanisms.
\end{abstract}

Keywords- small-scale model; active earth pressure; continuous mode; discontinuous mode; shearing band.

\section{INTRODUCTION}

Earth pressure problems are always encountered in retaining structures such as retaining walls, sheet pile bulkheads, cofferdams, bridge abutments, basement walls of buildings etc. Evaluation of earth pressure is of practical significance for the design of these retaining structures and it is a key research subject in soil mechanics and geotechnical engineering. Although results of full-scale model tests are more trustworthy, the costs to conduct such tests are very high. Scale model is a powerful tool for the verification of the earth pressure theory and the investigation of the mechanism of earth pressure.

A lot of research on small-scale model was carried out by Terzaghi into 1934 which is a big step in the history of the earth pressure study [1]. The results obtained showed that wall displacement has a significant effect on earth pressure. The earth pressure distribution on rigid retaining walls rotating about the base through field full-scale tests has been investigated [2]. A model of retaining wall has been developed in order to study the effect of wall displacement mode on earth pressure distribution [3]. The effect of the angle of inclination of the wall on the pressure of the grounds has also been studied [4].
Despite intense theoretical and experimental researches for more than 200 years, there remain considerable discrepancies between theoretical solutions and experimental results, due to the complexity of deformation field in granular bodies near the wall caused by the localization of the deformations (which is a fundamental phenomenon of granular material behavior). The localizations can appear single or multiple, depending upon initial and boundary conditions. They can be plane or curved. In shearing zones, pronounced grains rotations [5-8] and large strain gradients [9] are observed.

The thickness of shear localizations depends on various factors such as: mean grain diameter [9, 7, 10-12], pressure level $[10,13]$, initial void ratio $[7,13]$, direction of deformation [11], grains roughness and grain size distribution $[7,10,11]$.

Coulomb [14] indicated for the first time, the occurrence of shear zone during earth pressure tests. Darwin [15] illustrated that the explanation of the behavior of the granular bodies during earth pressure is not possible without taking into account shear localization. Several comprehensive experimental studies on earth pressure in sand were carried out between 1962 and 1974. During this period, a number of researchers [16-24] carried out experiments on the active and passive failure of dry sand deforming under plane strain conditions. The type of wall movement (passive wall translation) [18], active wall rotation about its top [22], passive wall rotation about its top $[16,17,22]$, active wall rotation about its bottom [23, 24], passive wall rotation about its bottom $[20,21]$, wall roughness [17, 24], wall flexibility (rigid wall and flexible wall) [24], initial density of sand (dense and loose) $[17,22]$, and influences of surcharge, were studied. The evolution of shear localization in sand was recognized by using the radiographic technique which is able to detect density changes. Different modes of shear zone during passive and active earth pressure tests depend mainly on the type of wall motion and surcharge. In passive tests with rigid walls rotating about the top, one or two curved shear zones were obtained in sand. Multiple curved shear zones of a similar shape were observed during tests with a wall rotating about the bottom. They occurred at the wall top and propagated towards the free boundary. During tests with translating rigid walls, slightly curved shear zones starting to form from the wall bottom, and secondary radial shear zones appears at the wall top. In active tests with rigid walls, nearly parallel straight zones or a mesh of 
intersecting parallel zones close to the wall (wall rotating around the bottom) or a single curved zone (wall rotating around the top) were observed. The details of these along with radiographs can be found in [25].

Numerical calculations $[26,27]$ revealed that the pattern of shear zones were easier to observe when a non-associated model of Coulomb-Mohr without dilatancy was assumed. The study carried out by Tejchman [28] with a uniform distribution of the initial index of the initial void ratio in sand showed that the calculated deformation field with a wall rotating around the bottom (passive and active case) was different from the experimental one [20, 23]. Further, this study showed that the geometry of calculated shear zones was influenced by the size of the sand specimen and its initial void ratio. The pattern of the induced shear zones was created also in the case of loose sand continuously subject to contractancy.

This paper wants to answer the following question: How shear zones will evolve when modifying the wall displacement mode? Will they follow logic evolution or random diffusion?

Wall movement is translating in the $\mathrm{X}-\mathrm{X}$ plane in continuous and discontinuous mode. So that the problem is mathematically determined, it is necessary to also set the boundary conditions on the two borders, free face and screen. The study will be related to horizontal free face not surcharged and vertical smooth wall, and this, for all tests.

The studied material is that of Schneebeli; light twodimensional material made up of dense rearrangement of cylindrical plastic rollers, simulating granular soil non-cohesive (dense sand).

\section{EXPERIMENTAL PROGRAM}

Description of active earth pressure was concretized by suitable experimental study. If one of assumptions theories of states ultimate equilibrium is that of a two-dimensional massif, this assumption cannot be ignored during any experimental work. The use of correlation pictures (Kisdef-7D software), allows qualitative visualization and especially the quantification of fields displacement evolution and those of plane objects deformations which will remain plane after transformation process. The principle of method consists in comparing two digital images. A first recording of granular soil surface is taken before deformation, whereas a second is taken after deformation [29].

The design of a small-scale model could as well as possible correspond to physical reality, which remains nevertheless very complex. It is thus a question of studying a physical phenomenon on a reduced dimensional reproduction in smallscale model [30].

\section{A. Modeling of granular soil}

The studied granular soil is represented by Schneebeli material which is used in various experimental approaches $[5,31]$. Schneebeli in 1957 showed that problems in soil mechanics with a granular non-cohesive material can be reduced to two dimensions [32]. The analogy consists in replacing a non-cohesive soil by a stacking of cylindrical, twodimensional rollers.

A lot of biaxial tests were carried out with cylindrical rollers made by dural [32-35] (dural or duraluminium is an alloy of aluminum and copper used in aeronautics because of its great strength and its more weak density that steel), rubber [36], PVC [37-40] and steel [41]. All tests showed that the material behavior is identical to dense sand.

The material studied in this paper, consisted of light plastic cylindrical rollers accumulation (Eighteen thousand rollers), as shown in Figure 1, cut out carefully showing the following characteristics:

- Light massif, dry density, $\gamma_{d}=3,5 \mathrm{kN} / \mathrm{m}^{3}$, grain density $\gamma_{s}=9 \mathrm{kN} / \mathrm{m}^{3}$ with plasticine, its cohesion is null and its natural friction angle $\varphi=10^{\circ}$.

- Indeformable rollers within sight of the actions applied thus simulating incompressible grains. The initially cylindrical rollers remain cylindrical after a process of transformation;

- Those rearrangements confer on granular soil a dense configuration.

- Length and diameter are respectively (70x2) in mm.

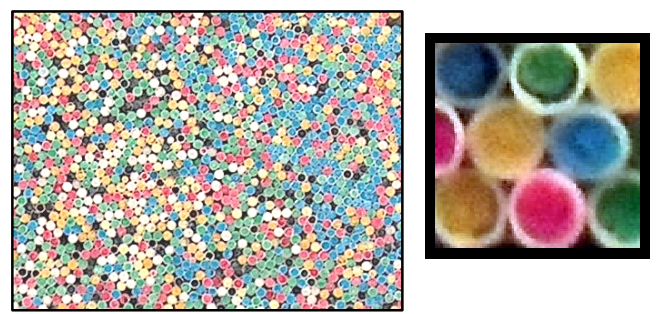

Fig. 1. Dense configuration of plastic cylindrical rollers

Rollers have an intrinsic porosity which is not held in account in our estimate. This is justified by the assumption of rollers incompressibility compared to implemented solicitations.

\section{B. Design of a small-scale model}

Figure 2 illustrates experimental small-scale model. Dimensions for the length, width and depth are respectively $800 \mathrm{~mm}, 500 \mathrm{~mm}$ and $100 \mathrm{~mm}$. Thus, a displacement wall of $30 \mathrm{~mm}$ is relatively low compared to the length justify a semiinfinite massif. Shear bands, when propagated, are not blocked by any other side wall. The $100 \mathrm{~mm}$ depth is sufficient to allow filling under the best stability conditions with rollers witch occupied a volume of $(550 \times 250 \times 70) \mathrm{mm}^{3}$. 


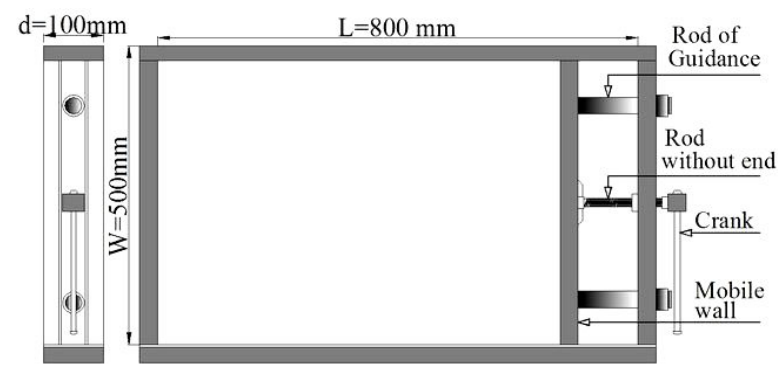

Fig. 2. Experimental small-scale model (Ref : 01-DPB-040404)

\section{Tests process}

Tests are carried in aim of qualitative comparison of rupture evolution between two displacement modes of rigid retaining wall known as continuous and discontinuous. Continuous mode describes wall displacement in an uninterrupted manner during all test process whereas discontinuous mode describes wall displacement marked by regular stops.

Tests are structured as follows:

- Wall Displacement in continuous mode: mobile wall carried out a translation in the X-X plane at constant speed of $0,22 \mathrm{~mm} / \mathrm{s}$ without interruption in time during tests process. Photographs are taken in a continuous way during all transformation process. Total displacement of mobile wall is $30 \mathrm{~mm}$.

- Wall Displacement in discontinuous mode: analog with continuous mode, however the mobile wall marks an interval of stop and a downtime; interval of stop is estimated at $0,75 \mathrm{~mm}$ when at the downtime, it is 3 seconds, and then the wall starts again.

- After each test, rollers are rearranged and compacted to eliminate dilatancy zones to have the same initial density. The depth must be maintained within $250 \mathrm{~mm}$. For each mode of wall displacement, the tests are repeated five (5) times by taking photographs with steps identical to tests preceding them.

- A post treatment by the software of correlation pictures Kisdef-7D allows the quantification and shearing bands evolution for studied modes.

\section{Result analysis by correlation pictures}

The treatment of active earth pressure tests is done by Kisdef-7D and it focuses in small deformations analysis by correlation pictures process. Digital pictures materializing transformations states are introduced into the software's database. Domain analysis is defined by the operator; it is subdivided in quadrilaterals by a virtual grid of $10 \times 10$ pixels on the initial image (see Figure 3). Deformed grid is found by comparing gray levels for each couple of pictures treated with high accuracy $\left(10^{-8}\right.$ pixels or $\left.0,19 \times 10^{-8} \mathrm{~mm}\right)$.

It should be noted that picture resolution (see Figure 4) is $3264 \times 1836$ pixels. Its confer ratio $\mathrm{mm} / \mathrm{pixel}$ of $0,19.3264$ pixels correspond at $620 \mathrm{~mm}$ in actual size. $620 \mathrm{~mm} / 3264$ pixels $=0,19$ thus 1 pixel $=0,19 \mathrm{~mm}$.

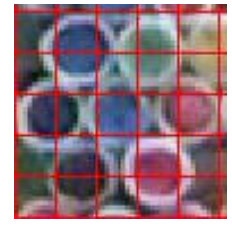

Fig. 3. Definition of quadrilaterals (10x10) pixels

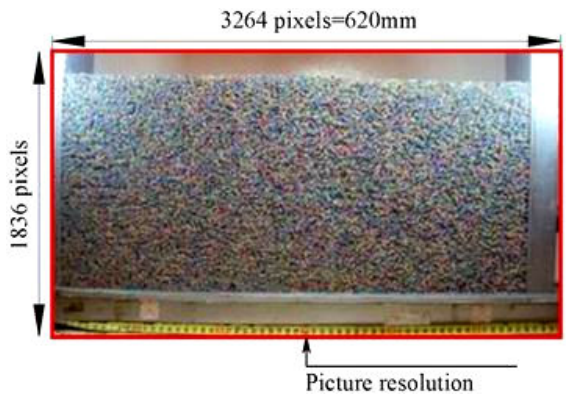

Fig. 4. Ratio $\mathrm{mm} /$ pixel

\section{E. Analysis mode and scale effect representation}

Shearing band is evolutionary for increment displacement and its research requires choosing an incremental type analysis. Therefore, photograph couples will be analyzed in incremental way i.e. (1-2), (2-3), (3-4), (49-50)... etc (see Figure 5).

Regarding scale effect representation, the software has two alternatives: local scale and total scale. Local scale proposes min and max values of maximum shearing for each analyzed couple, therefore varies from couple to couple. Total scale, proposes min and max values of maximum shearing for all analyzed couples.

All tests in continuous and discontinuous mode will show fluctuations in shearing bands intensities during transformation process, which will be visible only in local scale, as shown in Figure 5. Therefore, local scale will be adopted for each treated couple, as a total scale on all pictures couples will not allow observation of shear bands localization. On analysis 49 treating photographs 49 and 50 in continuous mode, shearing band evolution is definitely clearer on left figure (local scale), that on right figure (total scale). The same parameters are valid for discontinuous mode.

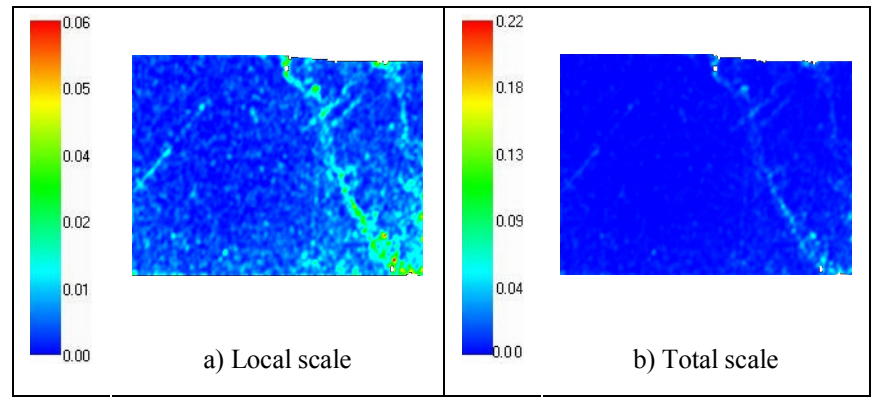

Fig. 5. Scale effect representation on localization shearing band: analyze 49/49 between photographs 49 and 50: Maximum shearing 


\section{F. Evolution of shearing bands in continuous and discontinuous mode}

A question however arises: "How shearing bands will evolve by modifying wall displacement mode? Will they follow logic evolution or random diffusion?"

Figure 6 represents failure evolution of granular soil following active earth pressure by shearing bands. A comparison between the two modes makes it possible to observe rupture evolution during transformation process.

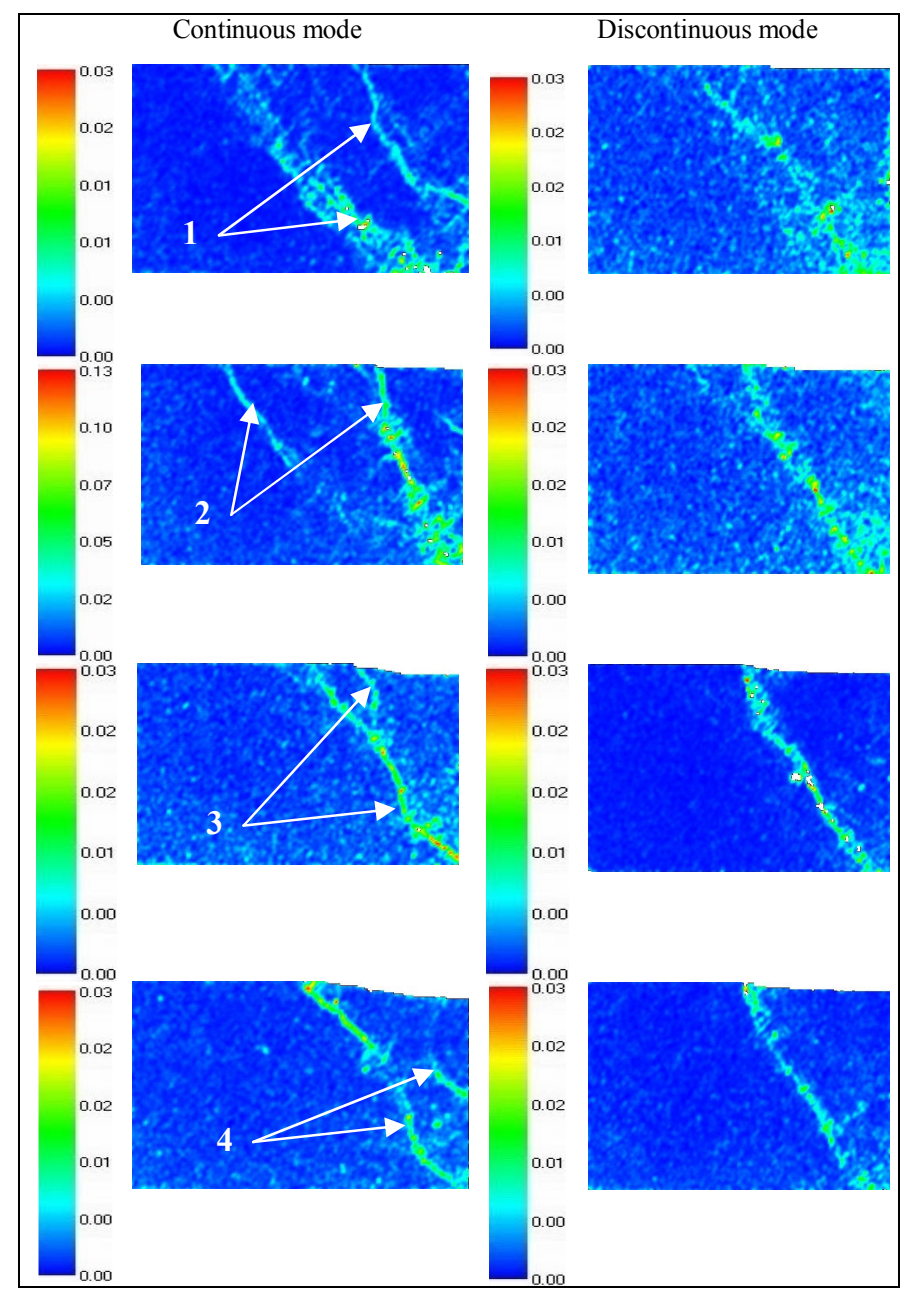

Fig. 6. Shearing bands evolution in continuous and discontinuous mode

When a granular soil is solicited in active earth pressure, a localization of deformation appears by shearing bands. Dilatancy phenomenon for dense soils is inevitable. The relative grain slips modify their rearrangement and the triangular configuration (dense state) become square (loose state) localized in the shearing band. Density distribution is not homogeneous (low in shearing band). When we continue to solicit soil in active earth pressure, it is similar to starting from an initial configuration with a heterogeneous distribution density, therefore slip is favored in the low density zone. If the process is reiterated, the deformation localization will settle more and more in the area in question.
However, for continuous mode displacement, in active earth pressure equivalent to a discontinuous sum of displacement mode, shearing bands propagation follows a diffusion logic letting multi mechanisms of failure appear (see Figure 6, labels 1-4).

\section{G. Shearing bands Evolution before and after each stop of wall movement}

Figure 7 illustrates shearing bands evolution for discontinuous mode displacement before and after each stop of mobile walls. Results are expressed in maximum shearing.

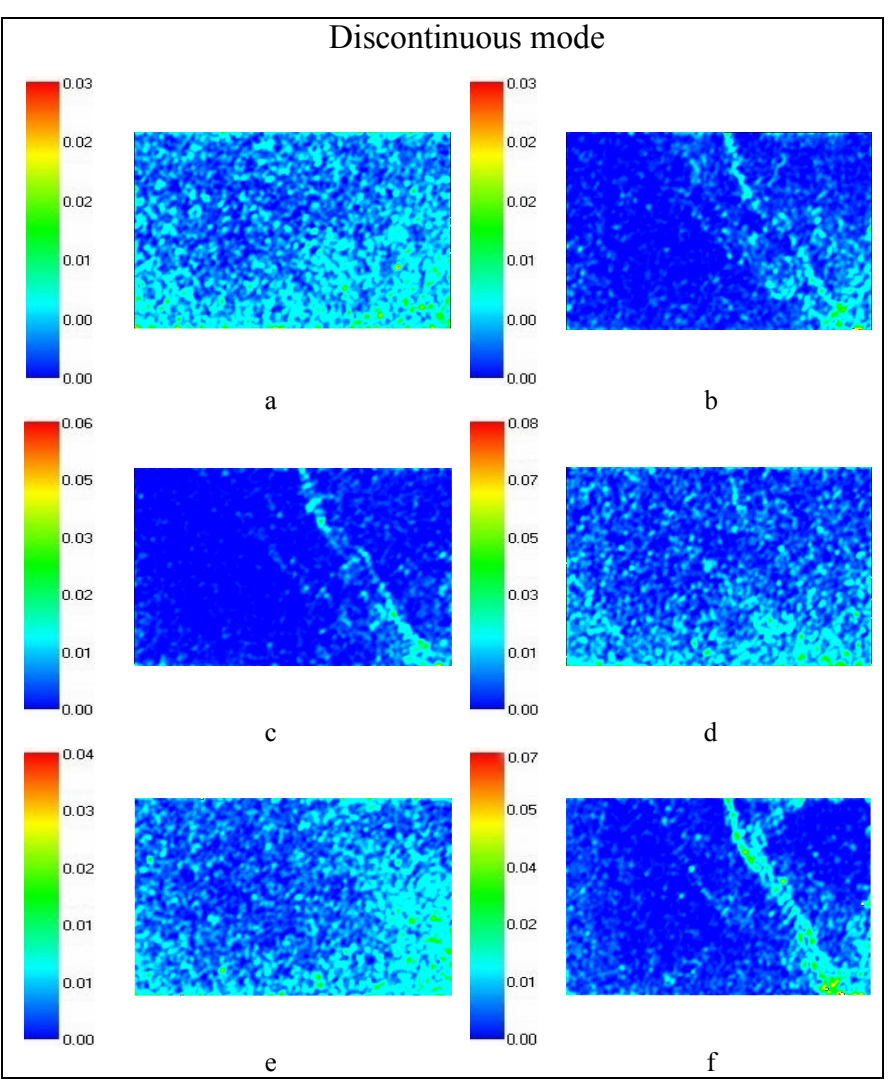

Fig. 7. Evolution of shearing bands before and after stop of wall movement

As shown in Figure 7a, at stop of wall movement, an equilibrium state is created in granular soil. With movement wall resuming, shearing band appears clearly (Figure 7b) and continues (Figure 7c). At time of second stop, a new equilibrium state is created with an heterogeneous density configuration (Figures 7d-7e). The last figure is spectacular; its shows the reappearance of shearing band exactly at the same place where it had disappeared when preceding wall movement had stopped.

\section{H. Repeatability}

For results validation, six repeatability tests are carried out under same conditions and lead to the same conclusions, as shown in Figure 8. 


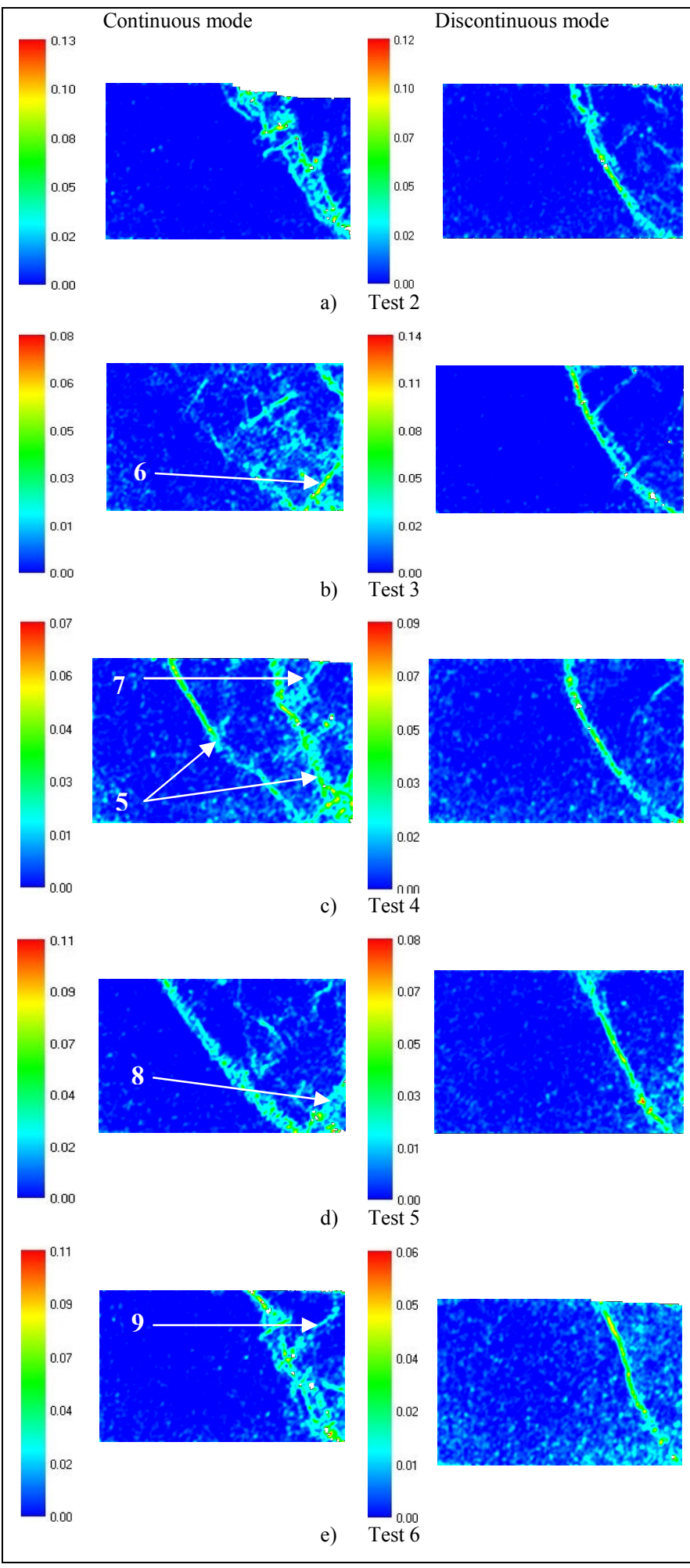

Fig. 8. Tests validation

Tests results expressed in maximum shearing intensity during discontinuous mode, (on the right of Figure 8) clearly show the preponderance of shearing band, while results on the left for continuous mode represent a disturbance of massif, governed by multiple shearing bands accompanied by parallel bands (Figure 8c, label 5), as well as perpendicular bands (Figure 8b-8c-8d-8e, labels 6-9). The difference is clearly shown.

\section{CONCLUSION}

At the last of this work, we arrive at the following conclusions:

- Realization of small-scale model simulating a granular soil subjected to active earth pressure made it possible to often highlight the evolution of deformations localization by shearing bands

- During the tests known as discontinuous, shearing bands evolution in dense massif favored dilatancy phenomenon, governs by low density in sheared zone. With the resumption of wall movement, the starter of a new shearing band is favored in sheared zone which is the least dense of the massif. This results strong deformation localization.

- With each stop of wall movement, an equilibrium state is created with a heterogeneous density configuration. With each resuming of wall movement, granular soil is solicited again and shearing band reappears exactly at the same place where it had disappeared at time of stop preceding wall movement.

- During tests known as continuous, shearing bands evolution follows logic diffusion letting appear strong disturbance governed by several shearing bands translating multi-mechanisms of failure.

- It was shown through this paper that failure evolution is significantly affected by displacement mode of mobile wall. The qualitative study shows a clear difference between continuous and discontinuous mode. This difference can be thorough in prospect while varying the interval of stop, the downtime as well as displacement speed of rigid retaining wall.

\section{REFERENCES}

[1] K., Terzaghi, "Large retaining wall tests", Engineering News Record Vol. 112, pp. 136-140, 1934

[2] M. Matsuo, S. Kenmochi, H. Yagi, "Experimental study on earth pressure of retaining wall by field tests", Soils and Foundations, Vol. 18, No. 3, pp. 27-41, 1978

[3] M. A. Sherif, Y. S. Fang, R. I. Sherif, " $K_{\mathrm{a}}$ and $K_{0}$ behind rotating and non-yielding walls", Journal of Geotechnical Engineering Vol. 110, No. 1, pp. 41-56, 1984

[4] Y. S. Fang, T. J. Chen, B. F. Wu, Passive earth pressures with various wall movements, Journal of Geotechnical Engineering, Vol. 120, No. 8, pp. 1307-1323, 1994

[5] M. Oda, J. Konishi, S. Nemat-Nasser, "Experimental micromechanical evaluation of strength of granular materials: effects of particle rolling", Mechanics of Materials, Vol. 1, pp. 269-283, 1982

[6] M. Uesugi, H. Kishida, Y. Tsubakihara, "Behaviour of Sand Particles in Sand-Steel Friction", Soils and Foundations, Vol. 28, No. 1, pp. 107118,1988

[7] J. Tejchman, "Scherzonenbildung und Verspannungseffekte in Granulaten unter Berucksichtigung von Korndrehungen”, Publication 
Series of the Institute of Soil and Rock Mechanics, University Karlsruhe, Vol. 117, pp. 1-236, 1989

[8] J. Geng, R. R. Hartley, D. Howell, R. P. Behringer, G. Reydellet, E. Clement, "Fluctuations and instabilities in granular materials" in: Bifurcations and Instabilities in Geomechanics, (J. Labuz and A. Drescher, eds.), Swets and Zeitlinger, 79-108, 2003

[9] I. Vardoulakis, Shear band inclination and shear modulus of sand in biaxial tests", International Journal for Numerical and Analytical Methods in Geomechanics, Vol. 4, No. 2, pp. 103-119, 1980

[10] F. Tatsuoka, M. Okahara, T. Tanaka, K. Tani, T. Morimoto, M. S. Siddiquee, "Progressive failure and particle size effect in bearing capacity of footing on sand", Proc. of the ASCE Geotechnical Engineering Congress, Vol. 27, No. 2, pp. 788-802, 1991

[11] F. Tatsuoka, M. S. Siddiquee, T. Yoshida, C. S. Park, Y. Kamegai, S. Goto, Y. Kohata, "Testing methods and results of element tests and testing conditions of plane strain model bearing capacity tests using airdried dense Silver Buzzard Sand", Internal Report of the University of Tokyo, 1-129, 1994

[12] F. Tatsuoka, S. Goto, T. Tanaka, K. Tani, Y. Kimura, "Particle size effects on bearing capacity of footing on granular material", in: Deformation and Progressive Failure in Geo-mechanics, (A. Asaoka, T. Adachi, and F. Oka, eds.), Pergamon, pp. 133-139, 1997

[13] J. Desrues, W. Hammad, "Shear banding dependency on mean pressure level in sand", Proc. Int. Workshop on Numerical Methods for Localization and Bifurcation of Granular Bodies, (E. Dembicki et al, eds.), Gdańsk, Poland, pp. 57-67, 1989

[14] C. A. Coulomb, Essai sur une application, Science et Industrie, Paris, 1775

[15] G. H. Darwin, "On the horizontal thrust of a mass of sand", Proc. Inst. Civ. Eng., Vol. 71, pp. 350-378, 1883

[16] J. R. F. Arthur, Strains and lateral force in sand, PhD Thesis, University of Cambridge, 1962

[17] R. G. James, Stress and strain fields in sand, PhD Thesis, University of Cambridge, 1965

[18] J. B. A. Lucia, Passive earth pressure and failure in sand, Research Report, University of Cambridge, 1966

[19] J. May, A Pilot Project on the cutting of soils, Research Report, University of Cambridge, 1967

[20] P. L. Bransby, Stress and strain in sand caused by rotation of a model wall, $\mathrm{PhD}$ Thesis, University of Cambridge, 1968

[21] A. Adeosun, Lateral forces and failure patterns in the cutting of sands, Research Project, University of Cambridge, 1968

[22] J. A. Lord, Stress and strains in an earth pressure problem, $\mathrm{PhD}$ Thesis, University of Cambridge, 1969

[23] I. Smith, Stress and strain in a sand mass adjacent to a model wall, $\mathrm{PhD}$ Thesis, University of Cambridge, 1972

[24] G. W. E. Milligan, The behaviour of rigid and flexible retaining walls in sand, PhD Thesis, University of Cambridge, 1974

[25] D. Leśniewska, Analysis of shear band pattern formation in soil. Habilitation, Institute of Hydro-Engineering of the Polish Academy of Sciences, Gdańsk, Poland, 2000

[26] D. Leśniewska, Z. Mróz, "Study of evolution of shear band systems in sand retained by flexible wall", International Journal for Numerical and Analytical Methods in Geomechanics, Vol. 25, No. 9, pp. 909-932, 2001

[27] D. Leśniewska, Z. Mróz, "Shear bands in soil deformation processes", in: Bifurcations and Instabilities in Geomechanics (J. Labuz and A. Drescher, eds.), Swets and Zeitlinger, pp. 109-119, 2003

[28] J. Tejchman, "Patterns of shear zones in granular materials within a polar hypoplastic continuum", Acta Mechanica, Vol. 155, No. 1-2, pp. 71-95, 2002

[29] P. Vacher, S. Dumoulin, F. Morestin, S. Mguil-Touchal, "Bidimensional strain measurement using digital images", Journal of Mechanical Engineering Science, Vol. 213, No. 8, pp. 811-817, 1999
[30] F. Darve, "Manuel de rhéologie des géomatériaux", Edition de l'association Amicale des Ingénieurs Anciens Elèves de l'Ecole Nationale des Ponts et Chaussées, 1987

[31] J. Lanier, P. C. Bonnet, "Experimental study of displacements and rotations of grains in 2D-granular media", Meeting TC13, Comitee on mechanics of granular materials (ISSMFE), Birmingham, 1993

[32] G. Schneebeli, "Une mécanique pour les terres sans cohésion”, Compte rendus des séances de l'Académie des Sciences. Paris, Vol. 243, pp. 2647-2673, 1956

[33] C. Coulet, "Etude du profil optimal des murs-voiles de soutenement", Thèse, Lyon : INSA de Lyon, 1977

[34] R. Albert, A. Houy, J. Raud, G. Verdier, "Etude à l'aide de modèles réduits de Datardeaux Massifs", Proc. of 5 Congrès Européen, Madrid, Vol. 1, pp. 231-239, 1972

[35] J. Verdeyen, V. Roisin, "Sollicitation des écrans souples de soutènement", in : Proc. Of 5 Congrès Int. , Paris, Vol. 1, pp. 422-426, 1961

[36] M. Oda, J. Konichi, S. Nemat-Nasser, "Experimental micromechanical evaluation of the strength of granular materials: effects of particle rolling", in. : Jenkins and Satake Eds. Mechanics of Granular Materials: New Models and Constitutive Relations, pp. 21-30, 1983

[37] R. Gourves, M. Mezghani "Micromécanique des milieux granulaires, approche expérimentale utilisant le modèle de Schneebeli", Revue Française de Géotechnique, Vol. 42, pp. 23-34, 1988

[38] H. Joer, J. Lanier, J. Desrues, E. Flavigny, " $1 \gamma 2 \varepsilon$ : A new shear apparatus to study the behavior of granular materials", Geotechnical Testing Journal, Vol. 15, No 2, pp. 129-137, 1992

[39] G. Tratapel, "Contribution à l'étude du comportement mécanique d'un milieu analogique bidimensionnel", Thèse: Génie Civil : Université Scientifique et Médicale et l'Institut National Polytechnique de Grenoble, 1977

[40] A. Misra, H. Jiang, "Measured kinematic fields in the biaxial shear of granular materials", Computers and Geotechnics, Vol. 20, No. 3-4, pp. 267-285, 1997

[41] R. Kastner, "Excavations profondes en site urbain”, Thèse Génie Civil, Lyon : INSA de Lyon, 1982 